\title{
Service Experiences of Undergraduate Engineers
}

Rachel Rupnow

Virginia Tech

Kirsten Davis

Virginia Tech

Rachelle Johnson

Virginia Tech

Elizabeth Kirchner

Virginia Tech

Jyotsana Sharma

Virginia Tech

Shahidur Rashid Talukdar

Virginia Tech

\section{Recommended Citation:}

Rupnow, R., Davis, K., Johnson, R., Kirchner, E., Sharma, J., Talukdar, S.R. (2018). Service experiences of undergraduate engineers. International Journal of Research on Service-Learning and Community Engagement, 6(1), Article 14. 


\title{
Service Experiences of Undergraduate Engineers
}

\author{
Rachel Rupnow \\ Kirsten Davis \\ Rachelle Johnson \\ Elizabeth Kirchner \\ Jyotsana Sharma \\ Shahidur Rashid Talukdar \\ Virginia Tech
}

\begin{abstract}
The study discussed in this article examined the impacts of service experiences on engineering students. The study sought to identify themes in the service experiences of engineering students through a qualitative research process involving interviews, open coding, and thematic analysis. The participants included six students studying civil engineering or related disciplines who took part in a service experience within the previous year. Participants responded to open-ended interview questions designed to collect detailed descriptions of their service experiences. Employing integrated open-coding techniques and thematic analysis of patterns that emerged from the interviews, the researchers identified three themes from the student responses: motivation, learning, and perspective. These themes, especially when examined through the lens of Mezirow's transformation theory, suggest that service experiences can motivate engineering students to participate in further service opportunities, seek jobs that involve actively serving others, and incorporate their attitude toward service into the engineering profession.
\end{abstract}

Keywords: service-learning, motivation, identity, student outcomes

Service experiences within higher education are often designed to expose students to diversity in hands-on learning environments and to influence professionals to serve throughout their careers. Service projects in resource-constrained cultures and contexts challenge students' technical ingenuity and expand their awareness of social responsibility (Bielefeldt \& Pearce, 2012). As a result, undergraduate engineering programs have sought to incorporate service opportunities into their curricula. Civil engineering in particular is a natural fit for using service projects as learning experiences. The first fundamental principle of the American Society of Civil Engineers (ASCE) code of ethics emphasizes that engineers should "use their knowledge and skill for the enhancement of human welfare and the environment" (ASCE, 2006, p. 1), an ethic closely associated with the purposes of service-learning and community service. Previous studies on the impacts of engineering service experiences have focused primarily on quantitative results and the reactions of students immediately following those experiences (e.g. Bielefeldt, Dewoolkar, Caves, Berdanier, \& Paterson, 2011; Bielefeldt, Paterson, \& Swan, 2010). Building on concepts from transformation theory (Mezirow, 1997, 2000), the researchers in the current study examined how servicelearning may lead to changes in student attitudes and behaviors. Specifically, the researchers interviewed civil engineering students up to a year after they had participated in service projects in an effort to learn about the potential transformative influence of those service-learning experiences. This article explores topics related to the key findings from the study, including how service experiences influenced the views of civil engineering students on the engineering profession, whether service led to development in their awareness and knowledge of the world, and whether such changes could become a form of intrinsic motivation for students to continue service in the long term.

\section{Literature Review}

Nearly half of all college students in the United States participate in some form of service during their college years according to a survey from the National Center for Education Statistics (Griffith \& Thomas, 2014). This emphasis on service may stem from a tradition of community service prioritized in the mission 
2 | International Journal of Research on Service-Learning and Community Engagement

statements of many U.S. higher education institutions (Felten \& Clayton, 2011; Holdsworth \& Quinn, 2012). Given college students' widespread involvement with service, the format and structure of service experiences can vary widely from school to school and even student to student. Some institutions do not require any service for graduation, whereas Tulane University, for instance, in the aftermath of Hurricane Katrina, has made service-learning courses a requirement for undergraduates (Mangan, 2010).

A number of terms have been used in the literature to describe student service, including community service, volunteerism, field education, internships, and service-learning (Phelps, 2012). Phelps (2012) provided a useful spectrum for differentiating these terms, ranging from volunteerism, which focuses on the service being provided, to internships and field education, which center on providing students with hands-on experience. Community service and service-learning are located in the middle of the spectrum because they tend to possess both service- and learning-related goals (Phelps, 2012).

\section{Defining Types of Service}

At its most basic level, community service involves voluntarily helping others or a community (Beehr, LeGro, Porter, Bowling, \& Swader, 2010). Though often required by colleges, community service programs and projects tend to lack specific academic goals; rather, they focus on encouraging students' personal development and social concern (Bowman, Brandenberger, Lapsley, Hill, \& Quaranto, 2010; Phelps, 2012). Improved relationships between colleges and local communities represent an additional but often understated benefit of community service programs (Holdsworth \& Quinn, 2012). Thus, while it places greater emphasis on student development than volunteerism, community service remains largely outside the academic realm and is typically viewed as an extracurricular activity (Bowman et al., 2010; Phelps, 2012).

By contrast, service-learning refers to a service tied directly to a course and has both service and academic goals (Bringle, Hatcher, \& McIntosh, 2006; Felten \& Clayton, 2011; Phelps, 2012; Swords \& Kiely, 2010). Felten and Clayton (2011) synthesized several definitions of service-learning and provided the following list of common characteristics:

- Advance learning goals (academic and civic) and community purposes;

- Involve reciprocal collaboration among students, faculty/staff, community members, community organizations, and educational institutions to fulfill shared objectives and build capacity among all partners;

- Include critical reflection and assessment processes that are intentionally designed and facilitated to produce and document meaningful learning and service outcomes. (p. 76)

While the second characteristic can also apply to well-run community service programs, the first and third are what differentiate service-learning. Bringle et al. (2006) emphasized specifically that service-learning should be credit-bearing, offer a broader perspective on the academic discipline of the course, and involve reflection on the service activity in order to improve student understanding of course content. Indeed, incorporating reflection into a service experience is a key benefit of tying student service to a course, as reflection can increase positive learning outcomes for students (Bringle et al., 2006; Phelps, 2012; Swords \& Kiely, 2010).

\section{Motivation to Participate in Service}

Motivation is the drive that compels an individual to maintain certain behavior (Bandura, 1977). According to Bandura's (1977) social learning theory, individuals learn by observing behaviors and their respective consequences. If a behavior's reward is considered worthy enough, the behavior is continued, and if not, the consistent repetition of the behavior is rejected. Several studies have explored what motivates students to participate in service experiences. Clary et al. (1998) found that when the personal goals of volunteers aligned with the received benefits of volunteering, the volunteers were both more satisfied with the experience and more likely to continue volunteering. Marta and Pozzi (2008) considered several possible motivations for sustained service and discovered that young people's volunteer identity and satisfaction with their volunteer organization were significant influences. Other studies have revealed that college 
Rupnow et al. / Service Experiences of Undergraduate Engineers $\mid 3$

students were motivated to perform community service by positive emotions inspired by volunteering, belief in a cause, desire to become better citizens, or desire to change community conditions (Soria \& Thomas-Card, 2014; Vecina Jiménez \& Chacón Fuertes, 2005). Soria and Thomas-Card (2014) also found that two thirds of students were at least partially motivated to serve by rewards inherent to service, and four fifths reported that their college community service experience made them want to continue serving after graduation. Some researchers have found that students performing service as part of a course requirement reported experiencing less intrinsic motivation and more extrinsic motivation than students engaged in nonrequired volunteer activities (Beehr et al., 2010). On the other hand, van Goethem, van Hoof, Orobio de Castro, Van Aken, and Hart (2014) found that the type of service and requirement of service did not have a significant effect on the impact of community service on the volunteers.

\section{Benefits and Impacts of Service Experiences}

Students who participate in service can receive several benefits. At the most basic level, students have expressed that such experiences help them step outside their comfort zones (Jones, Rowan-Kenyon, Ireland, Niehaus, \& Skendall, 2012; Welch \& Koth, 2013). Significant student growth, development, and learning are possible when individuals work with people unlike themselves and become aware of the challenges these individuals may face (Jones et al., 2012; Kiely, 2004; Prins \& Webster, 2010; Welch \& Koth, 2013). Service experiences can also expand students' knowledge of world issues and help them overcome misconceptions (Jones et al., 2012; McBride, Lough, \& Sherraden, 2012). On a more personal level, service can help students recognize and break down stereotypes, both during a service experience and at home (Jones et al., 2012). This contact with "others" often leads students to reflect on their own lives and perceptions, encouraging them to rethink their priorities, meaning in life, or career plans (Jones et al., 2012; Kiely, 2004; Prins \& Webster, 2010). Similarly, international service experiences have been shown to increase the international awareness, international social capital, and internationally related career intentions of volunteers (Jones et al., 2012; McBride et al., 2012).

In some cases, students experience spiritual development as a result of service-learning (Welch \& Koth, 2013). Such developmental changes have been referred to as transformative learning in the literature, or learning that results in a change of perspective. Transformative learning can lead to adjustments in assumptions and beliefs that allow an individual to become "more inclusive, discriminating, open, reflective, and emotionally able to change" (Mezirow, 2003, p. 58). Previous research has indicated that short-term study-abroad experiences could provide such transformative learning through reflection (Perry, Stoner, \& Tarrant, 2012), while a longitudinal study of service-learning participants revealed transformative changes in their political, moral, intellectual, cultural, personal, and spiritual perspectives (Kiely, 2004). In both cases, transformation theory provided a useful lens through which to understand experiences in which students' perspectives were challenged.

\section{Service Experiences of Engineering Students}

Engineering programs have increasingly begun to incorporate service-learning into their coursework. One common way of doing so is by providing service-based projects for students' lab courses or senior design capstone projects (Bielefeldt et al., 2011; Bielefeldt \& Pearce, 2012). Some schools have used disasters, such as Hurricane Katrina, to motivate service-learning experiences (Wilson, 2008). A few schools, such as the University of Massachusetts Lowell and the University of Vermont, have incorporated servicelearning throughout their entire engineering curriculum, including opportunities for students to participate during each year of their enrollment in the program (Bielefeldt et al., 2011). Even at schools where service is not included in the curriculum, extracurricular opportunities like Engineers without Borders and Engineers for a Sustainable World allow students to serve within the context of engineering (Bielefeldt \& Pearce, 2012). At schools offering service-based project options, student interest has been significant, with applications for these opportunities typically outnumbering the spaces available. Indeed, the interest is high enough that some school administrators have questioned whether students, in spending such substantial time on their service-learning projects, are neglecting their other coursework (Bielefeldt et al., 2011). 
In addition to the general benefits of service experiences, assessments of engineering servicelearning programs have revealed several discipline-specific learning outcomes. Regarding engineering design, service experiences encourage students to consider more complex constraints on their designs, including social, economic, environmental, political, and ethical implications (Bielefeldt et al., 2010). Researchers have also highlighted teamwork, communication, and leadership as skills developed through engineering service experiences (Bielefeldt et al., 2011, 2010; Bielefeldt \& Pearce, 2012). Service can also help students understand the social responsibility of the engineering profession (Bielefeldt \& Pearce, 2012). A number of studies have introduced the question of how service experiences can impact students' engineering identity. The preliminary results of these studies have indicated that students found service helpful in developing their understanding of what it means to be a "good engineer" and in connecting the technical and nontechnical aspects of this identity (Bielefeldt et al., 2010; Huff, Zoltowski, Oakes, \& Jesiek, 2013). In short, the literature has indicated a clear relationship between service-learning and the personal and professional development of engineering students.

\section{Theoretical Lens}

As noted earlier, transformation theory is commonly used to guide studies of experiential learning (Kiely, 2004, 2005; Perry et al., 2012). Mezirow (2000) described transformative learning as the process by which individuals transform their "taken-for-granted" mindsets and perspectives to make them more inclusive, open, and reflective (pp. 7-8). This process involves learning to critically assess one's feelings, values, and meanings through constructive discourse based on individual experience and the experiences of others and ultimately taking action based on one's adjusted perspectives (Mezirow, 1997, 2000). Mezirow (1997) used the term frame of reference to refer to the mindsets, perspectives, and values that define an individual's worldview, and further divided this concept into two dimensions: habits of mind and points of view. Habits of mind are abstract, habitual ways of thinking influenced by assumptions that may be cultural, social, economic, political, or psychological (e.g., ethnocentrism). These habits of a mind result in points of view when applied to specific situations or issues (e.g., beliefs and judgments of those outside one's culture; Mezirow, 1997). Transformative learning can occur by "elaborating existing frames of reference, by learning new frames of reference, by transforming points of view, or by transforming habits of mind" (Mezirow, 2000, p. 19). Mezirow (2000) also identified phases through which transformation occurs, from experiencing a disorienting dilemma, through self-examination, to ultimately integrating a new perspective on one's life.

These phases of transformation are often evident as students experience new environments through service-learning, which can often present disorienting dilemmas. Kiely (2005) provided a clear example of applying transformation theory in a service-learning context. Through a longitudinal study, Kiely characterized the phases of transformation as they occur in service-learning experiences. These involve a progression from contextual border crossing, through dissonance, personalizing, processing, and ultimately to connecting one's experience with the experiences of others. In another example, Jones et al. (2012) used Mezirow's $(1997,2000)$ and Kiely's (2005) work as a theoretical lens when studying student experiences in student learning. In qualitative research, it is common to approach a study using a theoretical lens rather than an explicit guiding framework (Creswell, 2003). For this study, we used concepts from Mezirow's transformation theory to guide the interpretation of our results.

\section{Method}

The purpose of this qualitative study was to explore the transformative experiences of civil engineering students participating in service projects. Though the literature has highlighted the personal and professional outcomes of service projects, most studies have utilized quantitative approaches. However, when examining human experiences, answers cannot be found in quantitative analysis; instead, the use of qualitative methodology has been recommended for such purposes by a variety of research methodologists (e.g., Moustakas, 1994). 
Specifically, this study adopted a phenomenological approach; that is, we sought to discover meanings that participants had made rather than searching for predetermined phenomena (Giorgi, 1997). Furthermore, by forming a research team composed of multiple researchers with varied academic backgrounds and disparate life experiences, we increased the likelihood of reading and interpreting participants' statements in multiple ways. Following the phenomenological tradition, we conducted indepth interviews of six participants, focusing on the lived experiences of individuals engaged in servicelearning and the personal or professional outcomes of these experiences (Moustakas, 1994). By allowing themes to emerge organically, we allowed for all possibilities to be true instead of injecting preemptive assumptions or propositions. The distinguishing feature of this study was that interviews were conducted two to 12 months after the service experience rather than conducting surveys immediately upon students' return from the service trips. This provided time for students to process the experiences, and in doing so, we hoped to capture specific examples of the lasting impact those experiences had on the participants.

\section{Participant Recruitment}

To build transferability (Anfara, Brown, \& Mangione, 2002), we recruited participants purposefully. According to the defined criteria for recruitment, participants needed to be 18 years of age or older and to have participated in a service experience within the year prior to the interview. After we secured approval from our institution's Internal Review Board (IRB), we contacted faculty members who taught servicelearning courses in the engineering department of a land-grant university in the eastern United States as well as leaders of campus organizations involved in service projects, and requested that they send recruitment invitations to appropriate students. We provided IRB-approved recruitment emails to these faculty members to use in the recruitment process. Ultimately, we recruited six students from undergraduate classes at the university. Table 1 summarizes the demographics of the participants. (Note that the actual names of participants have been changed to maintain confidentiality.) As compensation, participants were entered into a raffle to win a $\$ 10$ gift card.

Table 1. Summary of Participants

\begin{tabular}{llll}
\hline Pseudonym & Year & Major & Main Experience \\
\hline Patrick & Freshman & Civil Engineering & SL in Caribbean \\
Emma & Junior & Civil Engineering & SL in Caribbean \\
Adam & Sophomore & Civil Engineering & SL in Caribbean \\
Suzanne & $2^{\text {nd }}$-Year MS & Civil Engineering & Appalachia Service Project \\
Chris & $5^{\text {th }}$-Year Senior & Building Construction & SL at Panther House \\
Laila & $3^{\text {rd }}$ Year & Engineering & Studying water quality \\
\hline
\end{tabular}

Note. $\mathrm{SL}=$ service-learning

*Year numbering non-standard as exchange student

\section{Data Collection}

Before interviews were conducted, we formulated an interview protocol (Jacob \& Furgerson, 2012) and informed consent (Seidman, 2012). We also conducted peer debriefing (Anfara et al., 2002) to ensure that standard procedures would be enacted during all interviews. The interviews were semi-structured, inperson, and lasted approximately 45 minutes. Semi-structured interviews allow the interviewer to ask questions as they arise organically in conversation and are therefore beneficial when used in conjunction 
6 | International Journal of Research on Service-Learning and Community Engagement

with a phenomenological approach (Smith, 2008). The open-ended interview questions covered the following topics: a description of the service experience, the impact on the community being served, the influence on the student, and service experience since the trip. The interview questions built upon the ideas of motivation and transformative learning identified in the literature (Mezirow, 2003; Simsek, 2012), with the intent of exploring how students developed through their service-learning experiences. Specifically, the participants were encouraged to reflect and elaborate on how the experiences had changed their assumptions about the community and themselves.

\section{Data Analysis}

Each interview was transcribed and coded by the respective interviewer. Line-by-line and axial coding were used to generate the first round of emerging themes. Interviewers member checked by sending a summary of emerging themes to each participant for confirmation, identification of nuances, or retraction (Rossman $\&$ Rallis, 2012). Thematic analysis of each transcript was conducted through peer analysis (Anfara et al., 2002), resulting in the re-coding of each manuscript by at least three team members. Overall, each manuscript was coded four times, allowing the researchers to collaboratively discuss and process emerging themes through an iterative process. This hermeneutic approach was considered most appropriate because not only did this allow the participants' words to remain the focus of analysis, but emerging interpretations were tested repeatedly by peers. Once all transcripts had been coded, member checked, and peer reviewed, we launched into an extensive, painstaking group discussion to document emerging themes.

Because we did not enter the research with a predetermined theory or codebook, the themes were generated inductively. Each researcher looked for the central ideas fundamental to understanding participants' perspectives in their transcripts; these ideas were then brought together so that broader themes among the ideas could be identified. Three major themes emerged: motivation, learning, and change in perspectives. These were then split into subthemes in the context of the thick, rich data that were collected during the interviews. To ensure dependability, we used the coding-recoding strategy (Anfara et al., 2002), returning to individual transcripts and re-coding each transcript within the context of emergent themes. This process helped solidify the researchers' views of data collected. We also maintained an extensive group audit trail along with individual audit trails describing the researchers' processes, conversations, and decision making.

\section{Limitations}

The main limitation of this study was that, because it centered on a course project, it needed to be completed in one semester. This limited the methods available to the researchers as well as the number of participants for the study, reducing the number of stories and experiences from which the themes could develop. Nevertheless, the themes were consistent and strong enough within the sample to possibly persist across more participants. Including participants from a wider variety of service trips may have enhanced the researchers' ability to make such comparisons. Additionally, it would have been helpful to have conducted follow-up interviews and to have had access to participants' blogs or journals for additional coding and triangulation.

\section{Reflexivity}

The research team comprised graduate students from six different departments. During group thematic analysis, researcher reflexivity (Rossman \& Rallis, 2012) became a consistent part of peer discussions. As each researcher had studied and practiced in different fields, the process of meaning making was very different for each researcher. While these unique perspectives provided greater insight into the data we had collected, it also required greater communication skills and disciplined methods of defining each theme thoroughly so that all researchers could code consistently. 


\section{Participant Descriptions}

\section{Results}

Patrick, a Caucasian Air Force cadet who switched from civil engineering to international studies, spoke of having a "heart for service" and of putting "service before self." As a freshman, he participated in a loosely structured service experience building a clinic and delivering medicine in the Caribbean. Working among people who possessed very little, he nevertheless found generosity and selflessness. Reveling in hard, hot work, he found a community with a kindred "heart for service." A year after returning, he described his intention of participating in service experiences throughout his life, working to build a world of selflessness and community.

Emma was a Caucasian junior majoring in civil engineering with a focus on water resources. Before her service trip to the Caribbean during the previous summer, she had not participated in community service or traveled abroad. After her trip, she was excited about service and how it connected to her civil engineering major, and she had pursued several service experiences since her return, including a trip to a city with a water contamination crisis, Flint, Michigan.

Adam was a Caucasian sophomore from the civil engineering department. He was shy and uncomfortable with sharing too many details unless asked. He was part of a service trip that visited the Caribbean to help build a portion of the wall that would surround a new medical clinic. In the past, Adam had been involved with other volunteering projects in his community. He enjoyed being a part of different cultures and learning the different ways they do things (compared to the United States).

Suzanne was a Caucasian female graduating with a master's degree in civil engineering and was preparing to start a new engineering job in a large metropolitan area. Suzanne's service work included volunteer work addressing local housing needs and a service-learning project addressing animal adoption housing needs, the same project that Chris worked on. Suzanne believed every individual has an equal right to housing, and she dreamed of working internationally on the development of housing assistance programs. Demonstrating a determined altruism, Suzanne wanted to make her mark on the world as an engineer who "would love to help you."

Chris was a fifth-year senior graduating from the building construction program. A secondgeneration American - the son of Bolivian and Cuban immigrants - he presented himself confidently and was very willing to talk while he also worked to establish rapport with others through sustained eye contact. His main service-learning experience (i.e., building a local animal adoption center) was a domestic project located near the university.

Laila was a junior in environmental engineering who was soft-spoken and quiet but not shy. As an aspiring engineer, she was passionate about serving the poor and disadvantaged. In Morocco, her home country, she visited orphanages and helped disadvantaged children with their studies. She was interested in helping others by serving the community, although her long-term goal was to become a professor in engineering. Her service experience was in the same city where Emma's took place, Flint, Michigan.

\section{Summary of Themes}

The iterative coding process and peer analysis generated three major themes: learning, motivation, and perspective. Each major theme was divided into subthemes that capture the nuanced experiences recounted by the participants. Figure 1 depicts these thematic relationships.

\section{Learning}

It is not surprising that learning emerged as a prominent theme given that many students' experiences were classified as service-learning. Generally, students' learning appeared in two different forms: awareness at a personal level and knowledge of specific skills relevant to a profession. 
Figure 1. Diagrammatic representation of emerging themes for participants on service trips.

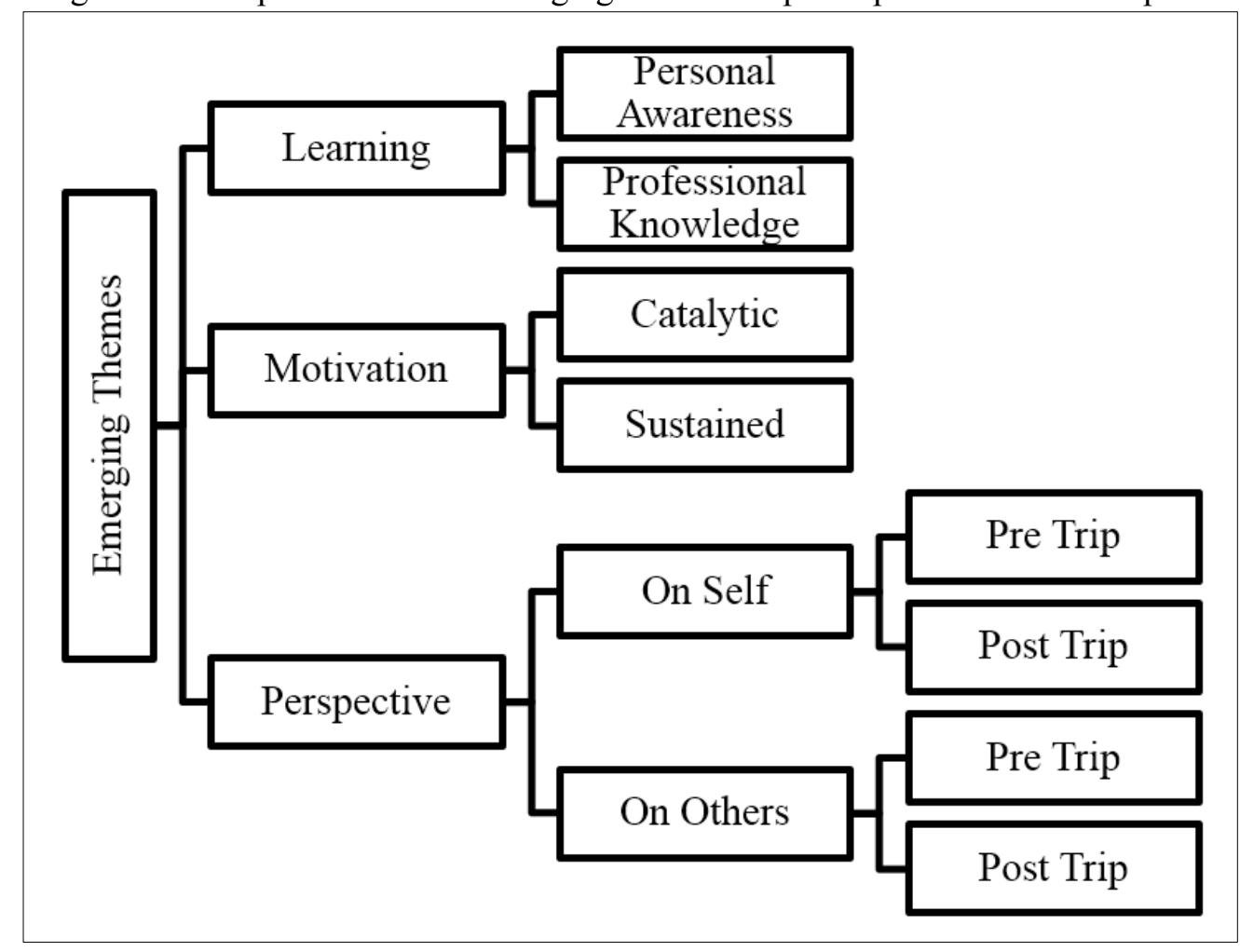

Personal awareness. The awareness theme included individuals' enhanced cognizance of the political, social, economic, and cultural constructs both at the service-trip location and at home. For example, Emma, who went to the Caribbean, noted differences from her home's social and cultural norms:

Not being able to flush my toilet paper. That was a huge shock. And ... having to carry like a two-liter water bottle around all the time ... that was also very shocking. Yeah ... traffic is crazy, driving around in traffic was terrifying. Because like everybody's honking all the time, everybody talks all the time ... like communication is constant, and when you're not talking, you're beeping your horn because that's how you talk!

Laila, participating in community water testing, gained greater awareness of the calamitous implications of failed infrastructure: "Many, many students abandoned schools.... like it was about 30,000 students. They did not go to schools anymore, which was ... very surprising for me." As an exchange student from North Africa, Laila's awareness was also made more profound by the irony of witnessing the failure of neglected civil infrastructure in a developed country to which she had traveled to study engineering.

This subtheme highlights the new habits of mind participants developed after their trips as a result of exposure to different experiences, especially different cultures and social contexts. Furthermore, the trips offered opportunities to learn new frames of reference.

Knowledge. The knowledge component of learning comprises both technical skills and soft skills - that is, those attributes that enable a person to interact effectively and amicably with others. Participants described recognizing an increase in their soft skills. Chris, an outgoing individual who worked on construction projects, said, "I had to adapt my skills, and I had to adapt to listen more and learn more before I just start hitting something with something." Knowledge also included professional skills and the development of an enhanced understanding that would be directly applicable throughout an individual's career. For instance, Suzanne, a civil engineering major who also worked on construction-based service 
projects, appreciated the insight the heuristic experiences gave her, forcing her to consider real-world issues:

Having an eye for how things go ... in the field is definitely helpful when you're designing them in the office, because sometimes you don't think about how someone can get their hand in there with this drill if it's only three inches wide.

Although not all students reported an accrual of engineering skills associated with their service, they consistently reported gaining a greater awareness of the problems their service experiences attempted to address and their abilities to address those problems. Furthermore, as in Suzanne's case, development of knowledge could lead to the formation of different points of view in future work contexts.

\section{Motivation}

The second theme that emerged from the interview data was motivation. Two forms of motivation were observed: catalytic motivation, the initiating state of the student related to choosing to participate in service; and sustaining motivation, the long-term influence of service experiences resulting in the integration of service projects into one's future choices.

Catalytic motivation. Complex circumstances and factors culminate in an engineering student's initial choice to engage in service. In our study, participants' service backgrounds ranged from participation in service organizations (e.g., Boy Scouts) to casual individual community involvement, such as visiting orphans and reading to underprivileged children. Some, but not all, participants expressed deep dedication to service built on social norms and values. Patrick explained, "I feel like I have this heart of service," a motivation he attributed to family and identified as unique: "Having the ... the upbringing that I did of service as a Boy Scout... was very different than if you picked a random American out of the middle of the country."

Catalytic motivations included advancing one's career through a bolstered resume of exotic experience and diverse skills. Catalytic motivation was strong enough to overcome impediments such as travel costs and a burdensome course load-which surprised even the participants. As Patrick said, "I should not have taken that many credits ... so ... if I had been thinking about that it would have been a surprise to me [small laugh]." For others, burden and struggle were catalysts themselves. For instance, Emma, a junior civil engineering student who participated in a loosely planned construction project in the Caribbean, expressed her motivation in the following way:

I just wanted to get out of the country, you know, experience the world far away from everything that I knew so that I could be as uncomfortable as humanly possible. So that I could get the most growth out of the experience, pretty much.

Thus, the service in which the student engages may itself become the catalyst of long-term intent to reengage, indicating future action based on their new perspectives. Because we interviewed participants several months after their experiences, participants recounted their service subsequent to the service experience on which the interview focused, which captured a second component of motivation: sustaining motivation.

Sustaining motivation. This subtheme relates to the idea that students' service experiences become internalized, entering their complex stream of life events, informing their choices, and encouraging them to participate in future service experiences. Emma participated in a public health response to Flint's water-supply contamination crisis. In this dramatic, emergency scenario, she reported feelings of competence and power regarding her skills and chosen field: "You know, this is the Katrina of water resources. So ...I'm going to be a civil engineer so that I can stop that, and that will be huge. So, that was really invigorating." Possessing engineering skills had multilevel empowerment effects, and acquiring the ability to address large infrastructure problems became a sustaining motivation for service. In turn, Emma expressed an urgent obligation to use her skills in the future: 
10 | International Journal of Research on Service-Learning and Community Engagement

Because I think for sure now I want to be working in water resources. I want to make sure that nobody ever gets poisoned by lead, ever again. And, I mean, the whole system is a mess, like they didn't have any maps of the pipes, so they didn't know where the lead was, so that they could fix the lead. And, I...you just got to stop it.

Service experiences served as contexts for civic responsibility in which participants reported revelations of diverse human experiences. This influenced both their catalytic and sustaining motivations, resulting in searches for similar experiences.

\section{Perspective}

The final theme evident in the data was perspective. For this study, perspective was defined as the lens through which individuals perceive and make meaning of the world around them. This theme was divided into two distinct categories: perspective "on self" and perspective "on others."

Perspective on self. This subtheme captures how the participants thought about or made meaning of their service trips and what beliefs and values they did or did not apply in their lives after their experiences. It highlights participants' critical reflection on their previously taken-for-granted beliefs and on future actions they might take in their personal lives. For example, when describing his service experience, Adam said,

You know, just learn about other cultures in the world and other people. And their experiences, so I can take that back and apply it to things I've learned in school, and then apply it to my personal values as well.

Suzanne, observing how hard poor families must work just to make ends meet, questioned her own lifestyle, saying, "It made me feel, not ashamed, but I should be doing more to ... just, do I need four couches?"

Perspective on others. This subtheme explains how individuals' social, cultural, and intellectual experiences changed their view of the people they were spending time with during their service trips. For example, Suzanne, noticing the lack of equity in opportunities, said, "I think when you're young you don't understand that a homeless man could have a college degree and could have just one bad opportunity or something." Before leaving for her service trip, Laila had researched Flint, where she would be volunteering, by watching videos of people engaged in violence in the streets on YouTube and news channels. However, she reported how her perspective on the people in the community changed after she got to know them:

From what I watched on those videos, they ... only show violence. They show that people are violent. But actually [the people] were fine. They weren't [violent] ... They were nice. They are upset with the situation, because I think it is quite normal to be upset not to have a safe drinking water but generally they were not really [violent] ... like I didn't notice any violence in their character. They talked normally and behaved normally.

Change over time. Later rounds of analysis revealed that the "on self" and "on others" themes could be divided into "pre" and "post" subcategories, representing the change some participants experienced in their perspectives as a result of their service experiences. Thoughts, beliefs, values, and assumptions held before the service trip were included in the "pre" category; changes in thoughts, beliefs, values, and assumptions, as well as changes in behavior were placed in the "post" category. Most of the participants indicated that their perspectives "on self" and "on others" changed as a result of their service trip. These changes persisted months after the trips concluded, indicating lasting changes to students' habits of mind. 


\section{Discussion}

Each of the three main themes revealed through this study-learning, motivation, and perspective-reflects previous findings in the literature on student service (Jones et al., 2012; Kiely, 2004; Soria \& Thomas-Card, 2014), suggesting that engineering service projects have impacts similar to those of other service projects. Moreover, the motivation to continue to serve and changes in participants' perspectives provide evidence of transformative learning (Mezirow, 2003; Simsek, 2012).

\section{Service Learning and Engineering Identity}

Unique perspectives related to engineering service experiences emerged from this study. Students tended to view their service experiences through the lens of their engineering identity (Bielefeldt et al., 2010; Huff et al., 2013). For example, Suzanne noted the usefulness of working in the field for practical considerations as an engineer. This lens impacted both how students described their service experiences and how they interpreted their subsequent learning. Participants also tied their view of service to their role as an engineer, which intensified their desire to continue serving throughout their engineering careers (Bielefeldt \& Pearce, 2012). Emma, for instance, noted her obligation to use her engineering skills to prevent future catastrophes.

The participants were students in the civil engineering and building construction disciplines, which provide relatively clear connections to service opportunities and value service as a professional responsibility (ASCE, 2006). Nonetheless, engineering students have previously been shown to view the technical and social aspects of the profession separately (Huff et al., 2013). However, Adam stated that he intended to apply the cultural lessons he learned to his studies and future career. Indeed, the study findings support the emerging conception of engineering as a helping profession (Beam, Pierrakos, Constantz, Johri, \& Anderson, 2009; Chachra, Kilgore, Loshbaugh, McCain, \& Chen, 2008) and confirm that service experiences can be an important way for engineers to develop that identity.

\section{Implications for Service-Learning}

In contrast to previous studies, we conducted our interviews two to 12 months after the students returned from their service experiences, allowing us to examine how the students viewed their experiences after some reflection, which is essential for transformative learning. It was clear that for many students in the study, the initial service experience spurred further service. Several students had joined service clubs or gone on subsequent service trips after their catalytic service experience. Students also indicated that they had searched for internships and future jobs that would allow them to pursue engineering in a service context. One student even changed his major to international studies, which aligned better with his views on how service could play out in his career. Observing the decisions made by students in the wake of their initial service experience lends credibility to the idea that service experiences can impact students' motivation to continue serving. These results align with one of the few longitudinal studies on service experiences, which revealed that students maintained this strong desire to serve even years after their trips (Kiely, 2004). The fact that many participants continued to pursue service after they had returned and intended to do so in the future suggested sustained transformation in attitudes resulting from the service experiences. Further, Mezirow $(1997,2000)$ maintained that transformation should ultimately result in action based on changes in assumptions and perspectives. Continued service is one indication that students have in fact experienced transformative learning.

\section{Implications for Engineering Educators}

The study themes highlight several opportunities for engineering educators who are considering implementing service projects in their programs. First, service experiences can inspire personal development in engineering students, providing knowledge, skills, and perspectives that will benefit their future careers. The Accreditation Board for Engineering and Technology (ABET) has identified several student learning outcomes that it believes are important for successful engineering careers today (ABET, 2015). These outcomes include "the broad education necessary to understand the impact of engineering solutions in a global, economic, environmental, and societal context" and "a knowledge of contemporary 
issues" (ABET, 2015, p. 3). Thus, incorporating service experiences into an engineering curriculum can play an important role in developing successful engineers as well as achieving ABET accreditation within an engineering program.

A second consideration for engineering educators is the opportunity that service-learning provides to motivate students to exercise social responsibility through their engineering work. The participants in this study came back to their engineering studies motivated not only to participate in other service projects, but to identify career opportunities that would allow them to continue serving others. Such motivation is important in a world where engineering challenges are increasingly complex and tied to moral, ethical, and political implications (Bielefeldt \& Pearce, 2012). By helping students develop this motivation in college, educators make it more likely that engineers will achieve the standard laid out in the ASCE code of ethics to use their "knowledge and skill for the enhancement of human welfare and the environment" (ASCE, 2006, p. 1).

\section{Conclusion}

In this study, we identified motivation, learning, and perspectives as major themes in engineering students' service experiences. Initial catalytic motivations to participate in service varied from a desire to serve fellow people to a desire to challenge oneself. During their service trips, participants developed awareness of the world and new knowledge and skills. They learned about the communities they were serving, which motivated them to think about their own homes in different social, political, cultural, and economic contexts. Participants developed skills through their service-learning trips that could be applied in their future careers, including both professional skills (e.g., communication, teamwork) and technical skills (e.g., knowledge of construction and engineering practices). Several of the participants experienced changes in their self-perceptions and in their perspectives on the people they served. Others changed their career plans and goals as a result of their service experiences. Participants also described a sustaining motivation to join future service-learning or community service trips since they viewed their previous trips as beneficial to themselves and the communities where they carried out their projects. Taken together, participants' interpretations of their experiences indicated increased self-reflection and awareness, in line with Mezirow's transformation theory.

Future studies should include larger numbers of participants and compare results across different types of service (e.g., community service vs. service-learning). It would also be valuable to gather more detailed data through a longitudinal approach, with multiple interviews conducted over a period of years following a service experience. Exploring how participants at different points in their studies reflect on their experiences could be of interest as well. For example, a study considering both undergraduate and graduate students would allow researchers to consider the influence of student development on servicelearning experiences. Understanding the differential impacts of different types of service trips would allow educators to design such experiences more intentionally to enhance student learning. Exploring differences between international and domestic service-learning, for instance, would be a useful contribution.

In an effort to design programs rooted in foundational learning or developmental frameworks, it would be useful to develop a model based on the service experiences of engineering students. Crossdisciplinary studies that examine catalytic motivations would provide additional insight into the development and promotion of service programs. In particular, while civil engineering aligns naturally with many service projects, it would be useful to consider other engineering disciplines to determine how catalytic motivations differ. Further, by identifying the catalytic motivations reported by college students, researchers could support similar efforts in secondary school or gap-year settings, which could be helpful in normalizing cultural participation and civic engagement at all educational levels. 


\section{Author Note}

Rachel Rupnow, Department of Mathematics, Virginia Tech; Kirsten Davis, Department of Engineering Education, Virginia Tech; Rachelle Johnson, Department of Building Construction, Virginia Tech; Elizabeth Kirchner, Department of Agricultural, Leadership, and Community Education, Virginia Tech; Jyotsana Sharma, Counselor Education, Virginia Tech; Shahidur Rashid Talukdar,Center for Public Administration and Policy, Virginia Tech.

\section{Correspondence}

Correspondence regarding this article should be addressed to Rachel Rupnow, Department of Mathematics, Virginia Tech, McBryde Hall 407, 225 Stanger Street, Blacksburg, VA 24061. E-mail: rachr15@vt.edu

\section{References}

Accreditation Board for Engineering and Technology. (2015). Criteria for accrediting engineering programs. Baltimore, MD: Engineering Accreditation Commission.

American Society of Civil Engineers. (2006). Code of ethics. Reston, VA: Author.

Anfara, V. A., Brown, K. M., \& Mangione, T. L. (2002). Qualitative analysis on stage: Making the research process more public. Educational Researcher, 31(2), 28-38. doi:10.3102/0013189X031007028

Bandura, A. (1977). Social learning theory. Englewood Cliffs, NJ: Prentice-Hall.

Beam, T. K., Pierrakos, O., Constantz, J., Johri, A., \& Anderson, R. (2009, June). Preliminary findings on freshmen engineering students' professional identity: Implications for recruitment and retention. Paper presented at the 2009 ASEE Annual Conference and Exposition, Austin, TX.

Beehr, T. A., LeGro, K., Porter, K., Bowling, N. A., \& Swader, W. M. (2010). Required volunteers: Community volunteerism among students in college classes. Teaching of Psychology, 37, 276280. doi:10.1080/00986283.2010.510965

Bielefeldt, A. R., Dewoolkar, M. M., Caves, K. M., Berdanier, B. W., \& Paterson, K. G. (2011). Diverse models for incorporating service projects into engineering capstone design courses. International Journal of Engineering Education, 27(6), 1206-1220.

Bielefeldt, A. R., Paterson, K. G., \& Swan, C. W. (2010). Measuring the value added from service learning in project-based engineering education. International Journal of Engineering Education, 26(3), 535-546.

Bielefeldt, A. R., \& Pearce, J. M. (2012). Service learning in engineering. In T. Colledge (Ed.), Convergence: Philosophies and pedagogies for developing the next generation of humanitarian engineers and social entrepreneurs (pp. 24-52). Hadley, MA: National Collegiate Inventors and Innovators Alliance.

Bowman, N., Brandenberger, J., Lapsley, D., Hill, P., \& Quaranto, J. (2010). Serving in college, flourishing in adulthood: Does community engagement during the college years predict adult well-being? Applied Psychology: Health and Well-Being, 2(1), 14-34. doi:10.1111/j.17580854.2009.01020.x

Bringle, R. G., Hatcher, J. A., \& McIntosh, R. E. (2006). Analyzing Morton's typology of service paradigms and integrity. Michigan Journal of Community Service Learning, 13(1), 5-15.

Chachra, D., Kilgore, D., Loshbaugh, H., McCain, J., \& Chen, H. (2008, June). Being and becoming: Gender and identity formation of engineering students. Paper presented at the 2008 ASEE Annual Conference and Exposition, Pittsburgh, PA.

Clary, E. G., Snyder, M., Ridge, R. D., Copeland, J., Stukas, A. A., Haugen, J., \& Miene, P. (1998). Understanding and assessing the motivations of volunteers: A functional approach. Journal of Personality and Social Psychology, 74(6), 1516-1530. doi:10.1037/0022-3514.74.6.1516

Creswell, J. W. (2003). Research design: Qualitative, quantitative and mixed methods approaches ( $2^{\text {nd }}$ ed.). Thousand Oaks, CA: Sage Publications.

Felten, P., \& Clayton, P. H. (2011). Service-learning. New Directions for Teaching and Learning, 128(Winter), 75-84. doi:10.1002/t1.470 
14 | International Journal of Research on Service-Learning and Community Engagement

Giorgi, A. (1997). The theory, practice, and evaluation of the phenomenological method as a qualitative research procedure. Journal of Phenomenological Psychology, 28(2), 235-260.

Griffith, J., \& Thomas, T. (2014). Do college youth serve others? How and under which circumstances? Implications for promoting community service. New Directions for Institutional Research, 162, 29-42. doi:10.1002/ir.20075

Holdsworth, C., \& Quinn, J. (2012). The epistemological challenge of higher education student volunteering: "Reproductive" or "deconstructive" volunteering? Antipode, 22(2), 386-405. doi:10.1111/j.1467-8330.2011.00844.x

Huff, J. L., Zoltowski, C. B., Oakes, W. C., \& Jesiek, B. K. (2013, October). Investigating how servicelearning alumni construct their engineering selves. Paper presented at the 2013 IEEE Frontiers in Education Conference, Oklahoma City, OK. doi:10.1109/FIE.2013.6685027

Jacob, S. A., \& Furgerson, S. P. (2012). Writing interview protocols and conducting interviews: Tips for students new to the field of qualitative research. The Qualitative Report, 17(6), 1-10.

Jones, S. R., Rowan-Kenyon, H. T., Ireland, S. M., Niehaus, E., \& Skendall, K. C. (2012). The meaning students make as participants in short-term immersion programs. Journal of College Student Development, 53(2), 201-220. doi:10.1353/csd.2012.0026

Kiely, R. (2004). A chameleon with a complex: Searching for transformation in international servicelearning. Michigan Journal of Community Service Learning, 10(2), 5-20.

Kiely, R. (2005). A transformative learning model for service-learning: A longitudinal case study. Michigan Journal of Community Service Learning, 12, 5-22.

Mangan, K. (2010, February 26). "Service learning" becomes the new standard at Tulane U. Chronicle of Higher Education, p. A14.

Marta, E., \& Pozzi, M. (2008). Young people and volunteerism: A model of sustained volunteerism during the transition to adulthood. Journal of Adult Development, 15, 35-46. doi:10.1007/s10804007-9033-4

McBride, A. M., Lough, B. J., \& Sherraden, M. S. (2012). International service and the perceived impact on volunteers. Nonprofit and Voluntary Sector Quarterly, 41(6), 969-990. doi:10.1177/0899764011421530

Mezirow, J. (1997). Transformative learning: Theory to practice. New Directions for Adult and Continuing Education, 74, 5-12. doi:10.1002/ace.7401

Mezirow, J. (2000). Learning to think like an adult: Core concepts of transformation theory. In J. Mezirow (Ed.), Learning as transformation: Critical perspectives on a theory in progress (pp. 333). San Francisco, CA: Jossey-Bass.

Mezirow, J. (2003). Transformative learning as discourse. Journal of Transformative Education, 1(1), 5863.

Moustakas, C. E. (1994). Phenomenological research methods. Thousand Oaks, CA: Sage Publications.

Perry, L., Stoner, L., \& Tarrant, M. (2012). More than a vacation: Short-term study abroad as a critically reflective, transformative learning experience. Creative Education 3(5), 679-683. doi:10.4236/ce.2012.35101

Phelps, A. L. (2012). Stepping from service-learning to SERVICE-LEARNING pedagogy. Journal of Statistics Education, 20(3), 1-22.

Prins, E., \& Webster, N. (2010). Student identities and the tourist gaze in international service-learning: A university project in Belize. Journal of Higher Education Outreach and Engagement, 14(1), 532.

Rossman, G. B., \& Rallis, S. F. (2012). Learning in the field: An introduction to qualitative research (3 ${ }^{\text {rd }}$ ed.). Thousand Oaks, CA: Sage Publications.

Seidman, I. E. (2012). Interviewing as qualitative research: A guide for researchers in education and the social sciences $\left(4^{\text {th }}\right.$ ed.). New York: Teachers College Press.

Simsek, A. (2012). Transformational learning. In N. Seel (Ed.), The encyclopedia of the sciences of learning (pp. 3341-3344). New York: Springer. 
Smith, J. A. (2008). Qualitative psychology. Thousand Oaks, CA: Sage.Soria, K. M., \& Thomas-Card, T. (2014). Relationships between motivations for community service participation and desire to continue service following college. Michigan Journal of Community Service Learning, 20(2), 5364.

Swords, A. C. S., \& Kiely, R. (2010). Beyond pedagogy: Service learning as movement building in higher education. Journal of Community Practice, 18(2-3), 148-170. doi:10.1080/10705422.2010.487253

van Goethem, A., van Hoof, A., Orobio de Castro, B., Van Aken, M., \& Hart, D. (2014). The role of reflection in the effects of community service on adolescent development: A meta-analysis. Child Development, 85(6), 2114-2130. doi:10.1111/cdev.12274

Vecina Jiménez, M. L., \& Chacón Fuertes, F. (2005). Positive emotions in volunteerism. The Spanish Journal of Psychology, 8(1), 30-35. doi:10.1017/S1138741600004935

Welch, M., \& Koth, K. (2013). A metatheory of spiritual formation through service-learning in higher education. Journal of College Student Development, 54(6), 612-627. doi:10.1353/csd.2013.0089

Wilson, D. (2008, October). Experiences of engineering students in post-Katrina service learning programs. Paper presented at the 38th ASEE/IEEE Frontiers in Education Conference, Saratoga Springs, NY. 